\title{
Building monitoring in Bishkek and Dushanbe by the use of ambient vibration analysis
}

\author{
Bojana Petrovic ${ }^{1,}$, Dino Bindi ${ }^{1}$, Marco Pilz ${ }^{1}$, Matteo Serio ${ }^{2}$, Sagynbek Orunbaev ${ }^{3}$, \\ Jafar Niyazov ${ }^{4}$, Farhad Hakimov ${ }^{4}$, Pulat Yasunov ${ }^{4}$, Ulugbek T. Begaliev ${ }^{5}$, Stefano Parolai ${ }^{2}$ \\ ${ }^{1}$ Helmholtz Center Potsdam - German Research Center for Geosciences, Potsdam, Germany \\ ${ }^{2}$ Serio Engineering \& Architectural Services and Consulting, www.serioconsulting.it \\ ${ }^{3}$ Central Asian Institute for Applied Geosciences, Bishkek, Kyrgyzstan \\ ${ }^{4}$ Institute of Geology, Earthquake Engineering and Seismology, Academy of Sciences of the Republic of Tajikistan, \\ Dushanbe, Tajikistan \\ ${ }^{5}$ International University of Innovation Technologies (IntUIT), Bishkek, Kyrgyzstan
}

\author{
Article history \\ Received October 6, 2014; accepted January 25, 2015. \\ Subject classification: \\ Building monitoring, Modal analysis, Seismic interferometry, Wave propagation in buildings, Ambient vibration.
}

\begin{abstract}
Within the framework of the EMCA - Earthquake Model Central Asia project, the cities of Bishkek (Kyrgyzstan) and Dushanbe (Tajikistan) were selected for building monitoring using measurements of seismic noise to obtain the dynamical properties of the buildings. Eight buildings of different construction types, date of construction and building height, both, Soviet-era and recently constructed buildings, were instrumented for a period of a few hours. In this study, an overview of the experiment is given, including a short description of each monitored building's structure and the performed installation. Preliminary results for a representative Soviet-era residential building in Dushanbe are presented. Modal analysis is performed using the Frequency Domain Decomposition (FDD) method to estimate the natural frequencies and the mode shapes. The wave propagation velocities in the two directions along the building axes are determined by an interferometric approach. Although the experimental set-up was not the optimal, valuable information about the dynamical characteristics of the buildings were still obtained.
\end{abstract}

\section{Introduction}

The high seismic hazard in Central Asia is a consequence of the collision between the Indian and Eurasian plates, taking place several thousand kilometers south. As a consequence of this tectonic setting, in the last two centuries, several strong earthquakes have occurred in this region [e.g., Kondorskaya and Shebalin 1982]. In particular, large earthquakes have struck the northern Tien Shan between the end of the 19th and the beginning of the 20th centuries $(M=7.3,1887$ Verniy earthquake; $M=8.2,1889$ Chilik earthquake; $\mathrm{M}=8.2,1911$ Kemin earthquake; $\mathrm{M}=6.9,1938 \mathrm{Chu}-$
Kemin earthquake). The occurrence of such large events makes Central Asia one of the areas of the world most prone to earthquake hazard, as confirmed by several studies performed at different spatial scales [e.g., Ulomov and the GSHAP Region 7 Working Group 1999, Abdrakhmatov et al. 2003, Erdik et al. 2005, Bindi et al. 2012, Ullah et al. 2015]. For example, all former capitals of Central Asia were destructed by earthquakes, such as Almaty (Kazakhstan), destroyed by the 1887, M 7.3 Verniy (former name of Almaty) earthquake and Ashgabat (Turkmenistan), destroyed by the 1948, M 7.3 Ashgabat earthquake, that probably led to more than 100,000 fatalities (http: / / earthquake.usgs. gov/ earthquakes/world/most_destructive.php). In particular, after the Verniy earthquake, a detailed survey of the effects generated by the earthquake in this region was performed (see Nurmagambetov et al. [1999] and references therein). The detailed description of the damage in Almaty provided an overview of the spatial variability of damage within the town and related them to the building type [Nurmagambetov et al. 1999]. More recently, two large earthquakes that struck the former Soviet Union (the 1988 Ms 6.8 Armenian and the $1995 \mathrm{Mw} 7.1$ Neftegorsk earthquakes) killed tens of thousands of people and destroyed more than $90 \%$ of the residential buildings [Geohazard International 1997]. The consequences of these earthquakes suggested that the seismic resistance of some types of the Soviet-time buildings was significantly lower than was officially stated [Geohazard International 1997]. Moreover, re- 

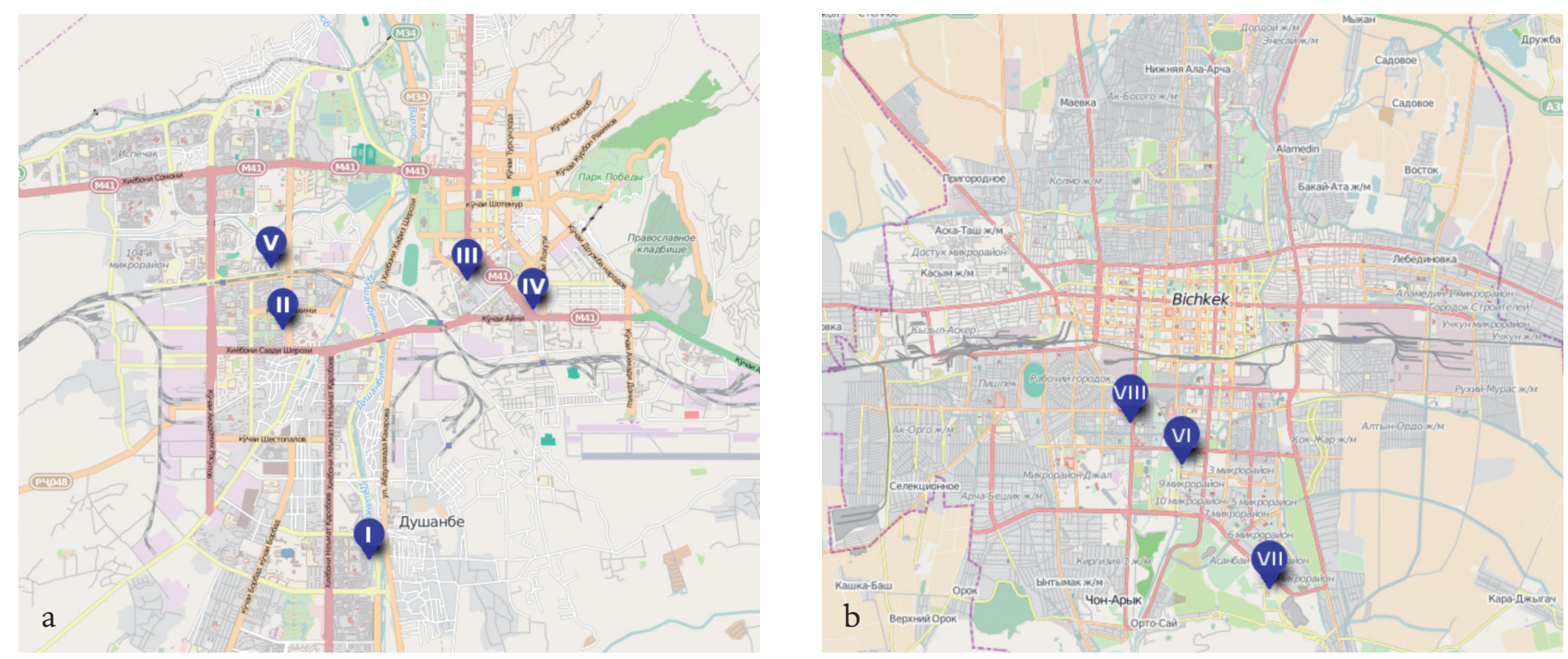

Figure 1. Map with the locations of the monitored buildings in (a) Dushanbe and (b) Bishkek.

cent studies [Erdik et al. 2005, Bindi et al. 2011] confirmed the high risk that capitals such as Bishkek (Kyrgyzstan) and Tashkent (Uzbekistan) are exposed to, and the need for strategies to reduce the uncertainties in the input parameters for risk assessment, both on the hazard and vulnerability sides. Finally, within the framework of EMCA (Earthquake Model for Central Asia) project, new approaches have been introduced for the estimation of the building inventory and vulnerability, combining multiple imaging sources and techniques from satellite remote sensing and omni-directional imaging [Wieland et al. 2012]. These approaches, which select optimal sampling and collection strategies and are based on the use of a fully probabilistic Bayesian networks-based information integration, have been applied to Bishkek [Pittore and Wieland 2013] and Dushanbe [Pilz et al. 2013, Niyazov et al. 2014].

Information about the dynamic properties of buildings obtained by ambient vibration measurements, e.g., the frequencies of resonance and mode shapes of the buildings, can be used for the identification of damage induced by future earthquakes. Using a recording in the free field, the level of shaking at the top of the building can be estimated in real-time by considering a simple structural model based on a single degree of freedom oscillator [Parolai et al. 2015]. Similarly, the response can be predicted at different floors by considering the interferometric transfer function to propagate vertically a shear-wave through the building in the earliest part of the motion, and adding the effect of the modal response in the later one [Cheng et al. 2015].

Since outcomes from experiments aiming at characterizing the seismic performance of the existing buildings and infrastructure in Central Asia can be used to assess the vulnerability of the building stock, in this study we present the seismic response of selected build- ings in Bishkek and Dushanbe obtained by the use of ambient vibration. Both, Soviet-era and modern constructions were monitored, considering residential and public buildings. In the following, we first describe the experiment, the selected buildings and the field work. Then, we discuss preliminary results about the modal analysis performed using frequency domain decomposition for one selected building. The characteristics of wave propagation for the same building, as retrieved by means of deconvolution interferometry, are presented as well.

\section{Site description}

In Dushanbe, one masonry and four reinforced concrete (RC) buildings were investigated. The locations of these buildings are shown in Figure 1a. In Bishkek (Figure 1b) one university (KSUCTA - Kyrgyz State University of Construction, Transportation and Architecture), one institute (KIS - the Kyrgyz Institute of Seismology) and one residential house were monitored by ambient vibration measurements. The selected buildings are representative of constructions in Central Asia for different periods. Some buildings were considered for their infrastructural importance, such as KSUCTA and the Serena Hotel. Finally, all three buildings in Bishkek are instrumented permanently by SOSEWIN installations and are part of a series of installations for evaluating the feasibility of an Earthquake Early Warning System (EEWS; Bindi et al. [2015]). Details about the instrumented buildings are given below.

I) 12 story monolithic reinforced concrete building (Figure 2,I).

The monitored building (Figure 3) is located close to a building of a similar type of construction, which is not connected to the building under investigation. The building was constructed in the middle of the 1980s and 

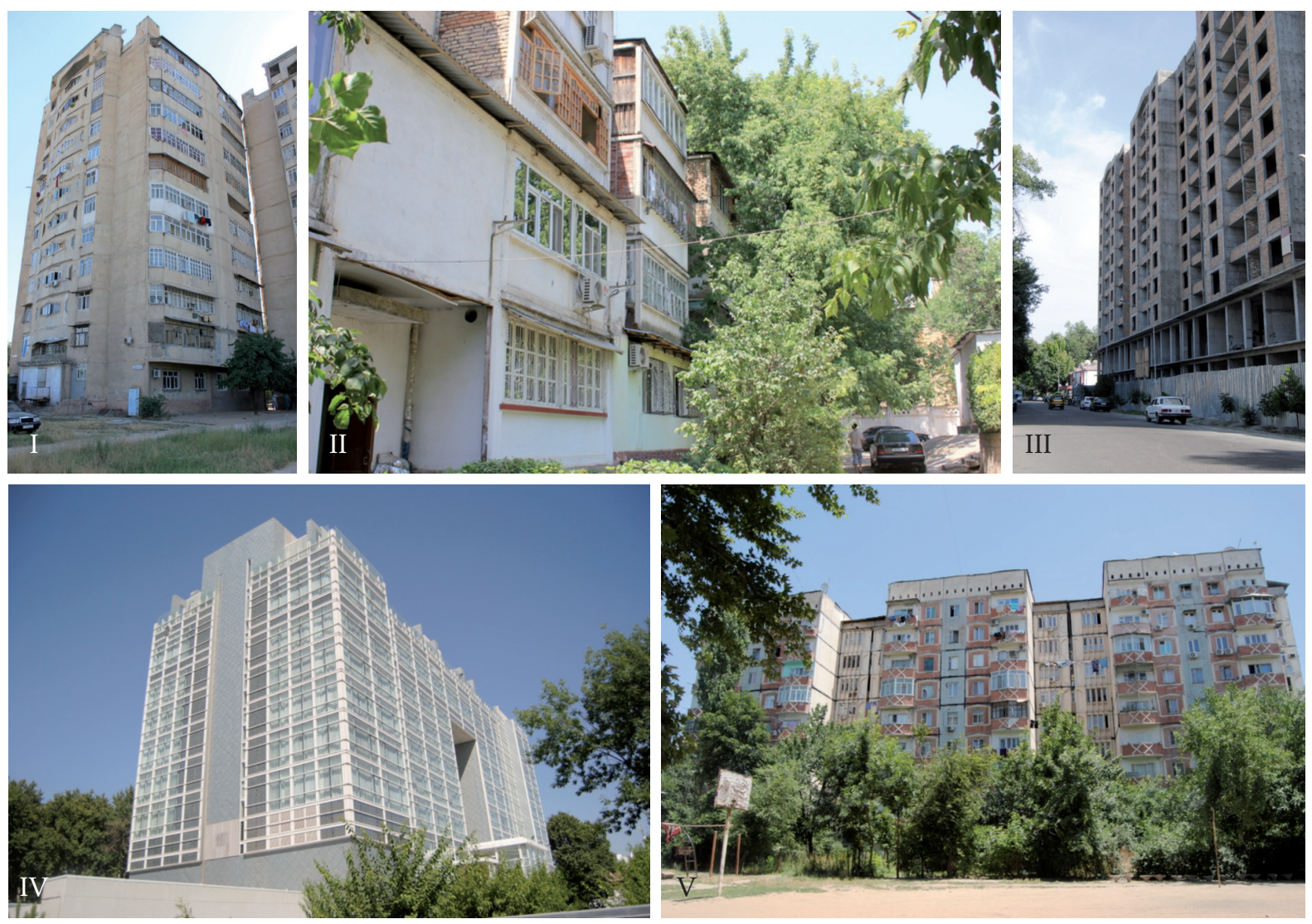

Figure 2. Photos of the 5 buildings in Dushanbe where ambient vibration measurements were performed. (I) 12 story monolitic RC building, (II) 4 story confined masonry building, (III) 12 story RC dual system building under construction, (IV) Serena Hotel and (V) 9 story reinforced large panel precast concrete building.

has a $20 \mathrm{~m} \times 20 \mathrm{~m}$ square shape. In the basement, offices and storerooms are situated. The longitudinal and transverse load-bearing walls are constructed of expanded clay, the basement walls of heavy concrete. The slabs are made of reinforced concrete, and the flat roof is of concrete without additional covering.

The building is situated on the terrace of the right bank of the river Dushanbinka. The area is composed of gravel and pebble soils. The geological structure of the site includes both, modern alluvial deposits and deposits of anthropogenic origin.

This building is representative of a residential building built in the 1980s in this area. Figure 3 shows a satellite image of the building and the footprint of the building floor arrangement including the locations of the instruments.

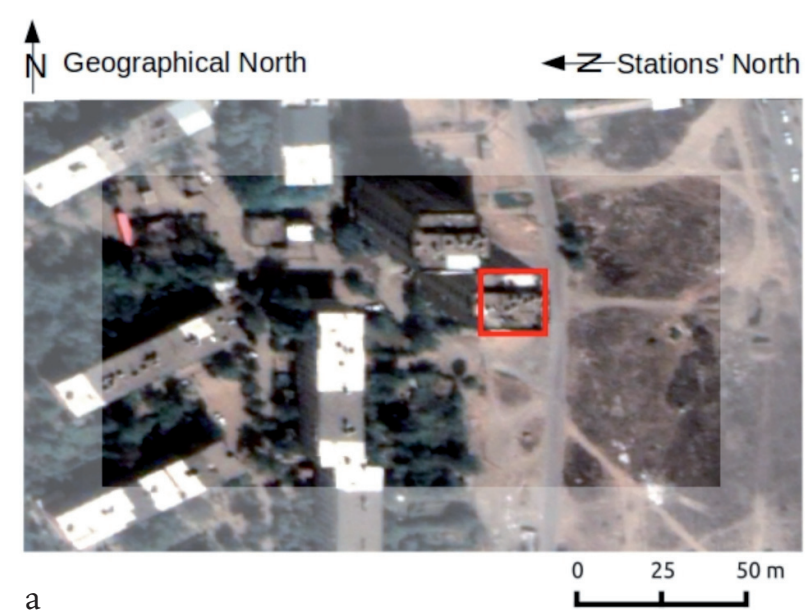

Figure 3. (a) Satellite image and (b) building floor plan of the 12 story monolitic RC building (Figure 2,I), showing the locations of the installed stations (red symbols).

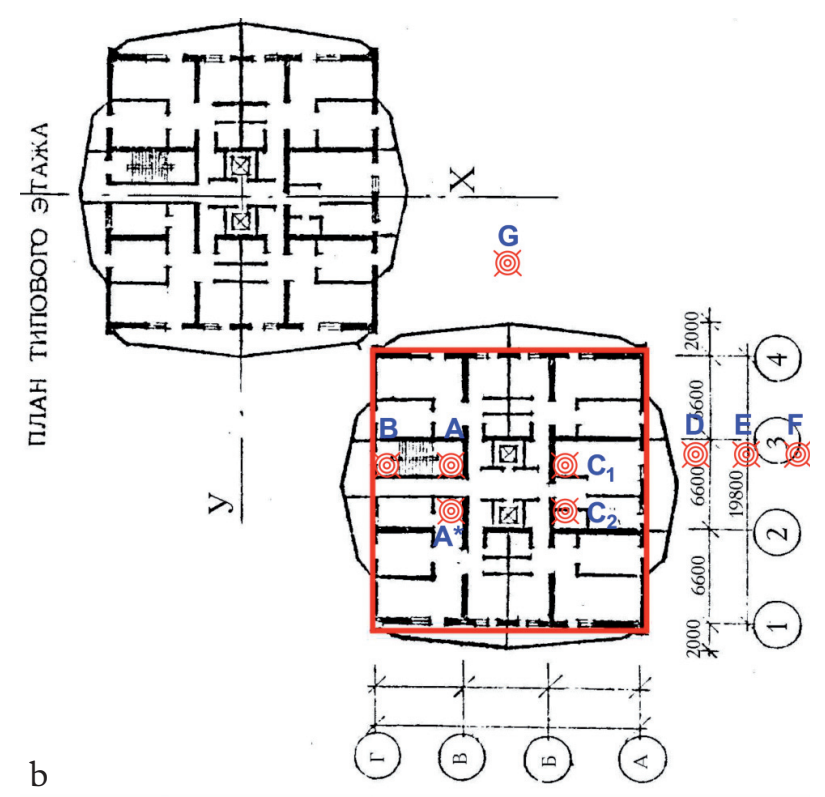



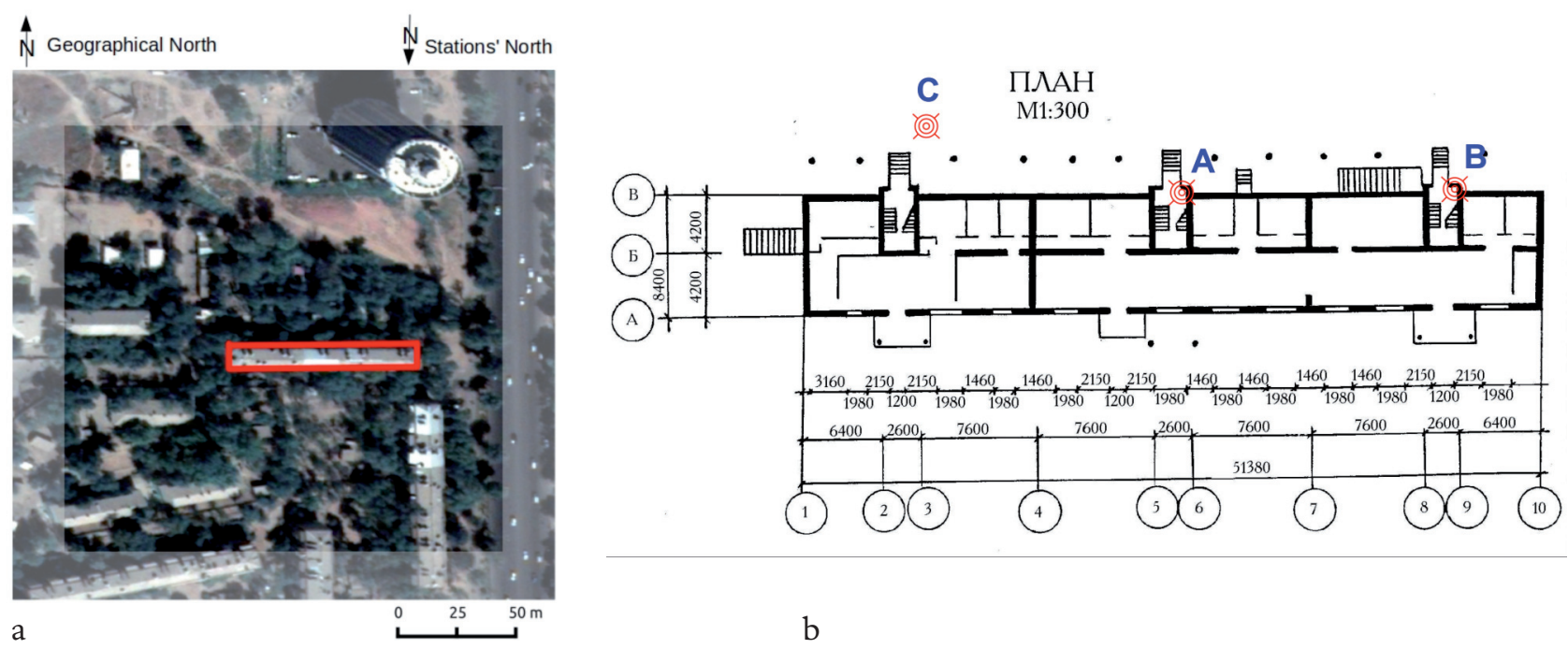

b

Figure 4. (a) Satellite image and (b) building floor plan of the 4 story confined masonry building (Figure 2,II), showing the locations of the installed stations (red symbols).

II) Four story confined masonry building.

This residential building was built in the 1970s (Figure $2 \mathrm{~b}$ ) and is composed of two individual units, connected by seismic isolation joints. The building is of a rectangular shape with overall dimensions of $51.0 \mathrm{~m} \times$ $8.4 \mathrm{~m}$, with no buildings located nearby (Figure 4). The building consists of bearing longitudinal walls. The foundation and basement walls are constructed of rubble concrete, the external walls of brick with cementlime mortar. The roof is pitched and hipped and made of wood-based sheets on rafters or purlins. The slabs are built of precast concrete panels with circular cavities. The building is situated next to the right bank of the river terrace Kafirnigan on Quaternary sediments (loam yellow-brown and gravel-pebble deposits).

III) 12 story reinforced concrete dual system building that was still under construction (Figure 2c).

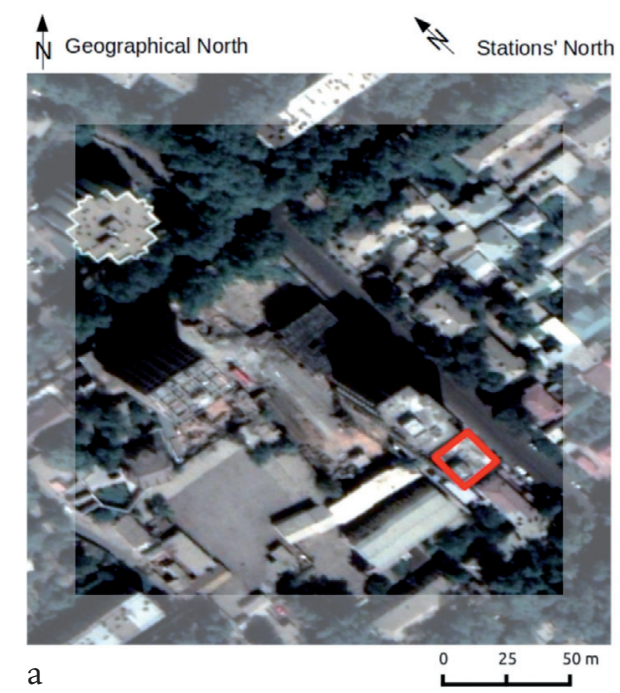

The building consists of 5 individual building units, that are separated by seismic isolation joints. The investigated building unit has a nearly rectangular footprint shape with dimensions of $21.0 \mathrm{~m} \times 20.7 \mathrm{~m}$. It is equipped with two elevators and a stairwell. The height of the first two floors above ground is $4.5 \mathrm{~m}$, the other floors have a height of $3.3 \mathrm{~m}$. The building has a dual frame-wall system, with both concrete and masonry exterior walls. The roof is a flat, cast-in-place beam-supported reinforced concrete roof, without additional covering. The slabs are cast-in-place beam-less reinforced concrete slabs. The building is located on loessial loam deposits.

IV) Serena hotel, built in 2010 (Figure 2d).

The Serena hotel is a 13 stories reinforced concrete building, consisting of a dual frame-wall system. The exterior walls are built of concrete and masonry. The

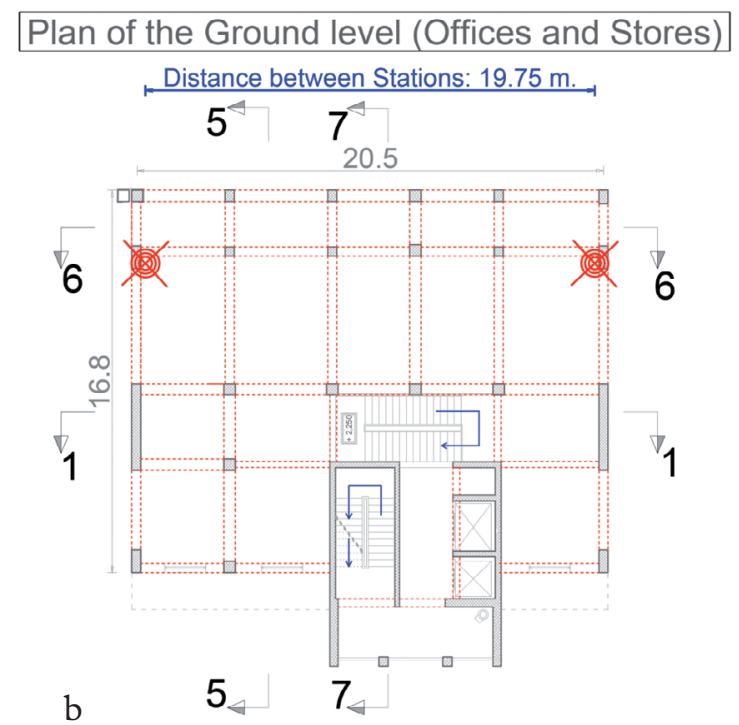

Figure 5. (a) Building floor plan and (b) cross-section of the RC dual system building under construction (Figure 2,III). The locations of the stations are marked with red symbols. 

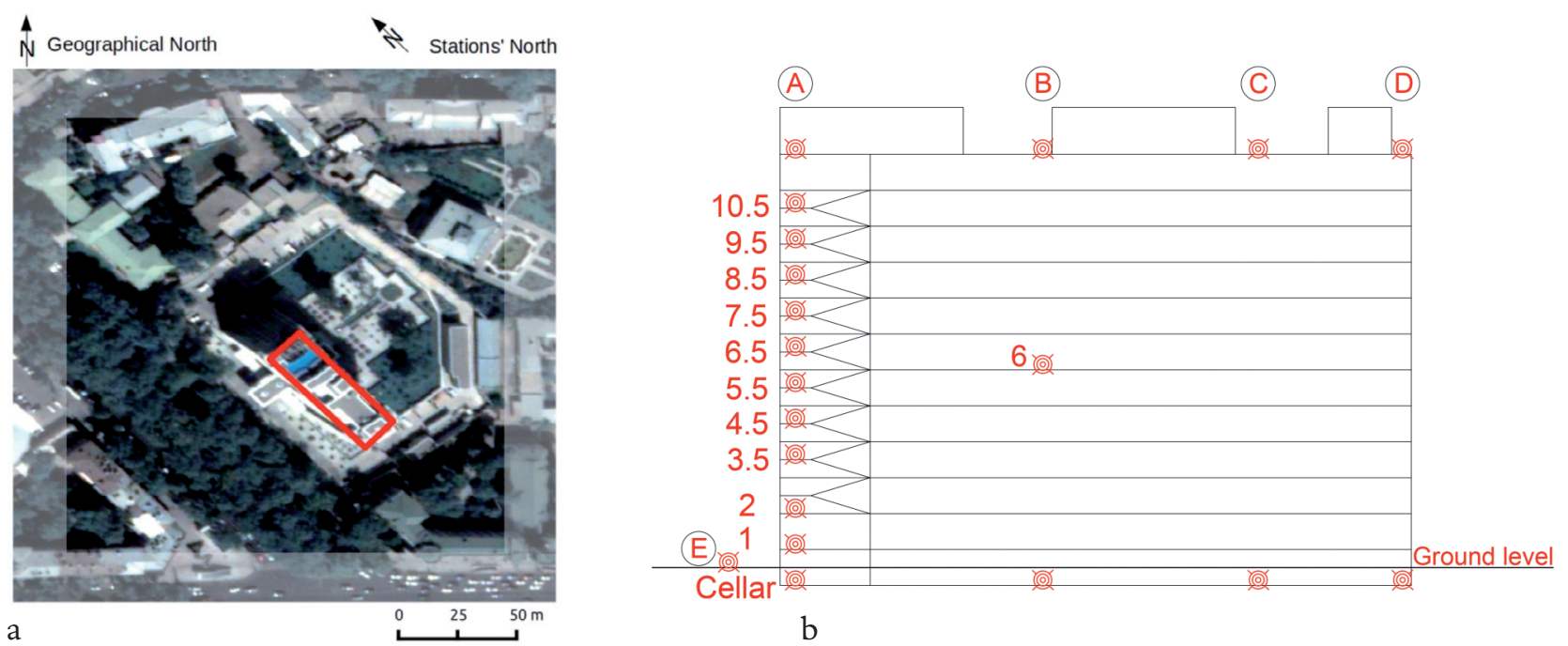

b

Figure 6. (a) Satellite image and (b) cross-section of the Serena Hotel (Figure 2,IV), showing the locations of the installed stations (red symbols).

building has a flat, cast-in-place beam-supported concrete roof and cast-in-place beamless reinforced concrete slabs. The footprint is approximately rectangular and it is detached from other buildings (Figure 6).

V) 9 story reinforced large panel precast concrete (PC) residential house (Figure 2e).

This example, built in the 1980s is composed of three individual units with rectangular footprint (Figure 7), that are separated by seismic isolation joints. It has transverse and longitudinal, internal and external bearing walls (of reinforced and single-aggregate concrete) with horizontal diaphragms of solid concrete slabs, that provide the spatial rigidity of the building. The roof is flat and made of concrete without additional covering. The building is situated in an area close to the III terrace right bank of the river Kafirnigan.

VI) KSUCTA, a reinforced concrete, precast con- crete 7 story building, built in the 1980s (Figure 8a).

KSUCTA has a regular structure and approximately L-shape $\left(120^{\circ}\right.$ angle between the two wings) with adjoining buildings on three sides (Figure 9). The exterior walls were built of concrete, the roof is a flat, precast concrete roof with a membrane covering and a reinforced concrete topping.

VII) KIS, a reinforced concrete, precast concrete 2 story building (Figure 8b).

The lateral load resisting system of this building is a non-ductile post and beam system. The building is made up of concrete exterior walls, a pitched roof with gable ends and a metal or asbestos sheet roof covering, and precast concrete slabs with reinforced concrete topping. The structure is regular and it has a $\mathrm{H}$ shape crosssection (Figure 10).

VIII) 12 story RC residential building, built in the
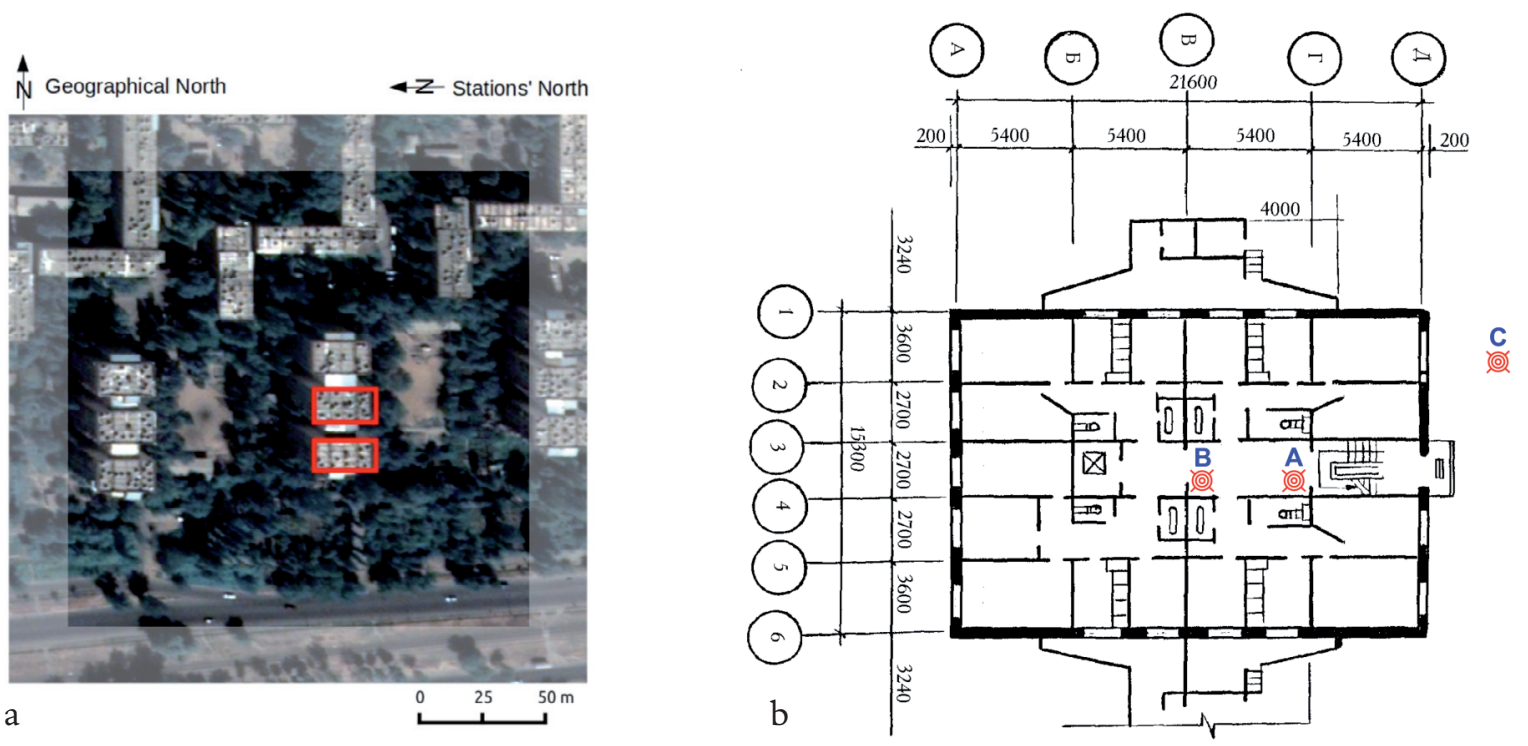

Figure 7. (a) Satellite image and (b) building floor plan of the 9 story reinforced large panel precast concrete building (Figure 2,V), showing the locations of the installed stations (red symbols). 

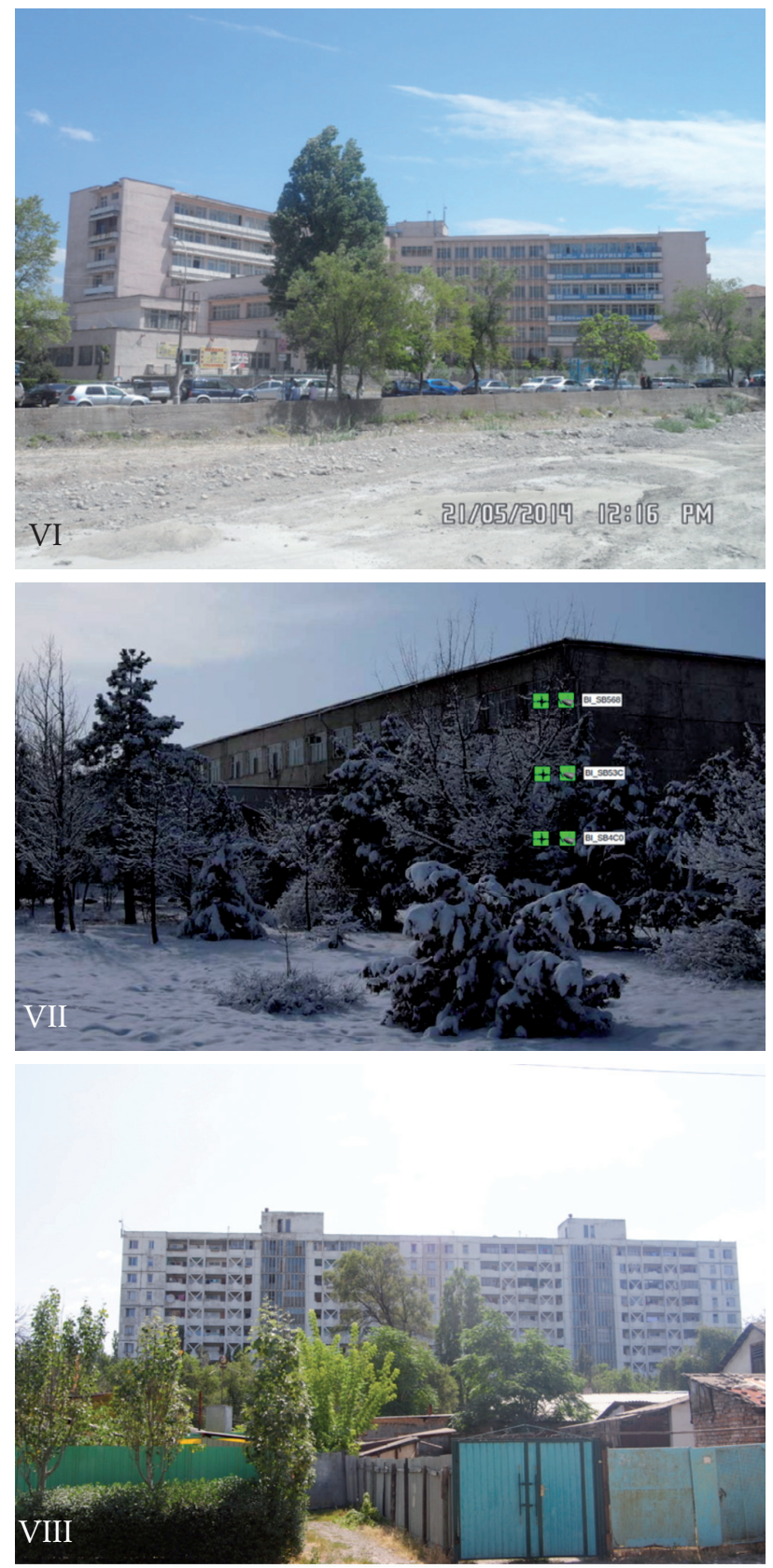

Figure 8. Photos of the 3 monitored buildings in Bishkek. (VI) KSUCTA, (VII) KIS and (VIII) 12 story RC building complex.

1980s (Figure 8c).

The structure is regular, and is composed of two adjacent buildings with a rectangular shape and adjoining buildings on three sides (Figure 11). The exterior walls are constructed of concrete, the roof is flat, built of precast concrete with reinforced concrete topping and a membrane roof covering, while the slabs are precast concrete slabs with reinforced concrete topping.

\section{Experimental set-up}

During summer 2013, ambient vibration measurements were performed in 5 buildings in Dushanbe (Tajikistan) and in 3 buildings in Bishkek (Kyrgyzstan), using 30 short period, 3 component L4C-3D Mark sen- sors ( $1 \mathrm{~Hz}$ natural frequency) connected to Earth Data Logger (EDL PR6-24) 24bit digitizers. The sampling rate was set to 500 samples per second, the gain of the preamplifier to 10 . The instruments were equipped with external GPS to facilitate the time synchronization of the instruments. However, it was not possible to receive the signal everywhere. Since most of the selected buildings are residential houses, the selection of the measurement points was constrained by logistic limitations. In particular, although not optimal from the monitoring point of view, the stations were generally installed along the corridors and sometimes in the staircases.

I) 23 stations were used for the monitoring of a 12 story monolitic RC building (Figure 2a), 17 stations were installed in the staircase (12 at position $A$ and 5 at position B on different floors, Figure 3b), 2 in the cellar and 4 outside at different distances from the building. 2 stations had problems in receiving the GPS signal and could be used only for some analyses where precise time synchronization was not required. 2 stations had other unknown functionality problems. In Table 1 , the functionality of all stations installed at positions A and B is listed.

II) In the four story confined masonry building (Figure 2b), 6 stations were installed at each of the two locations, $\mathrm{A}$ and $\mathrm{B}$, at different floors, in the left block of the building complex (Figure 4b). One station in the cellar had problems with receiving the GPS signal.

III) The 12 story dual system RC building under construction (Figure 2c) is the only building for which the building floor and section plans were available and the positioning of the stations was not limited. 15 stations were installed at two locations at 7 different floors (see Figure 5 for the exact position of the stations within the building, the building floor plan and section) and one outside. Since the station at the basement had some problems during the measurements, one station was moved from the 7 th floor to the basement.

IV) 19 stations (Figure 6b) were installed in the Serena Hotel (Figure $2 \mathrm{~d}$ ) and one outside. 12 stations were located at almost the same position at different floors, with some on the stairways and others in the corridor. The instruments were synchronized by receiving the GPS signal outside the building before and after installation.

$\mathrm{V})$ In the 9 story reinforced large panel precast concrete building (Figure 2e), 14 stations were installed in one buildings of the complex (Figure $7 \mathrm{~b}$ ), 5 at position $A$ and 9 at position $B$ at different floors. In addition, one station was installed outside.

VI) 27 instruments were installed in KSUCTA (Figure $8 \mathrm{a}$ ), with three stations outside (Figure $9 \mathrm{~b}$ ).

8 stations were installed at position $\mathrm{A}$, one at each floor, 7 instruments at position B. 12 stations were distributed at positions C-G at different floors. 8 of the sta- 

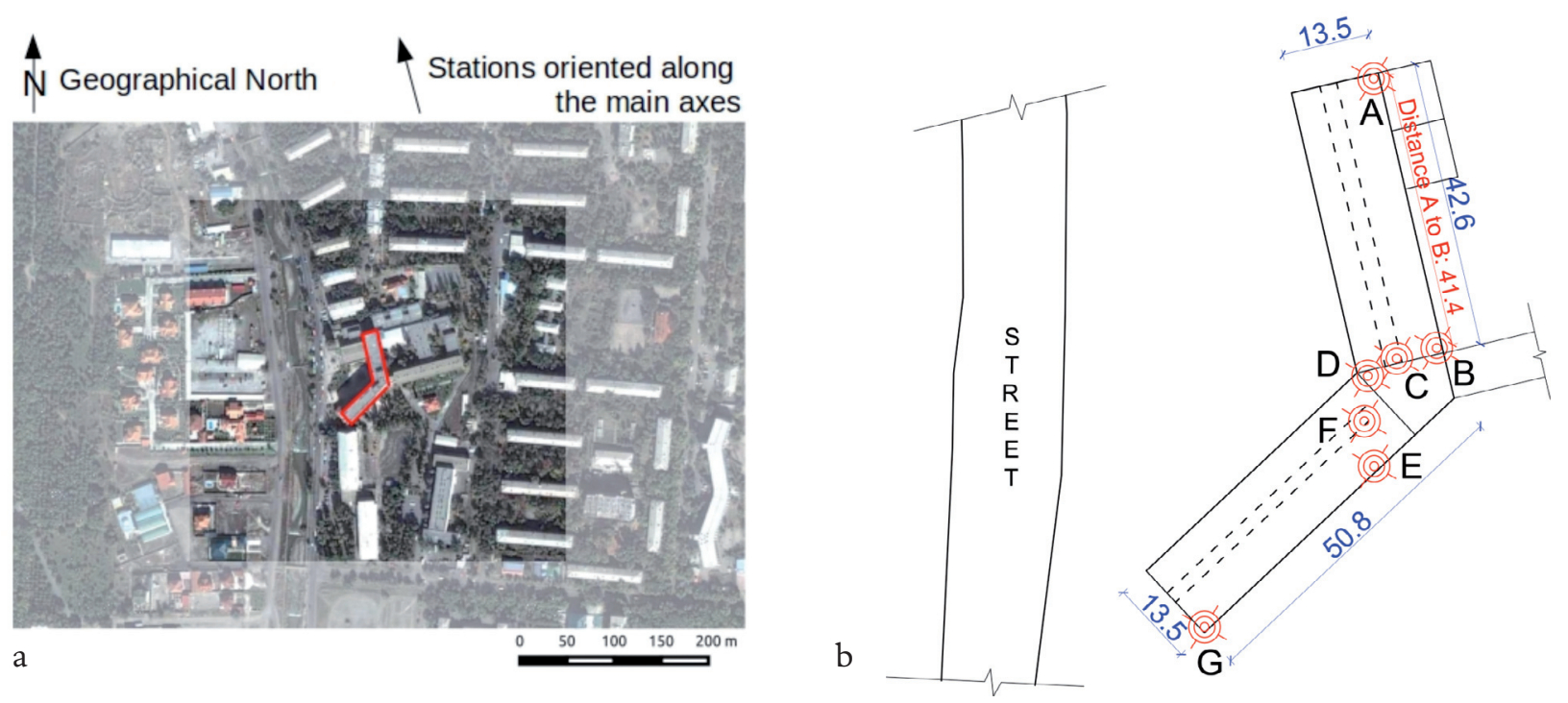

Figure 9. (a) Satellite image and (b) simplified building floor plan of KSUCTA (Figure 2,VI), showing the locations of the installed stations (red symbols).
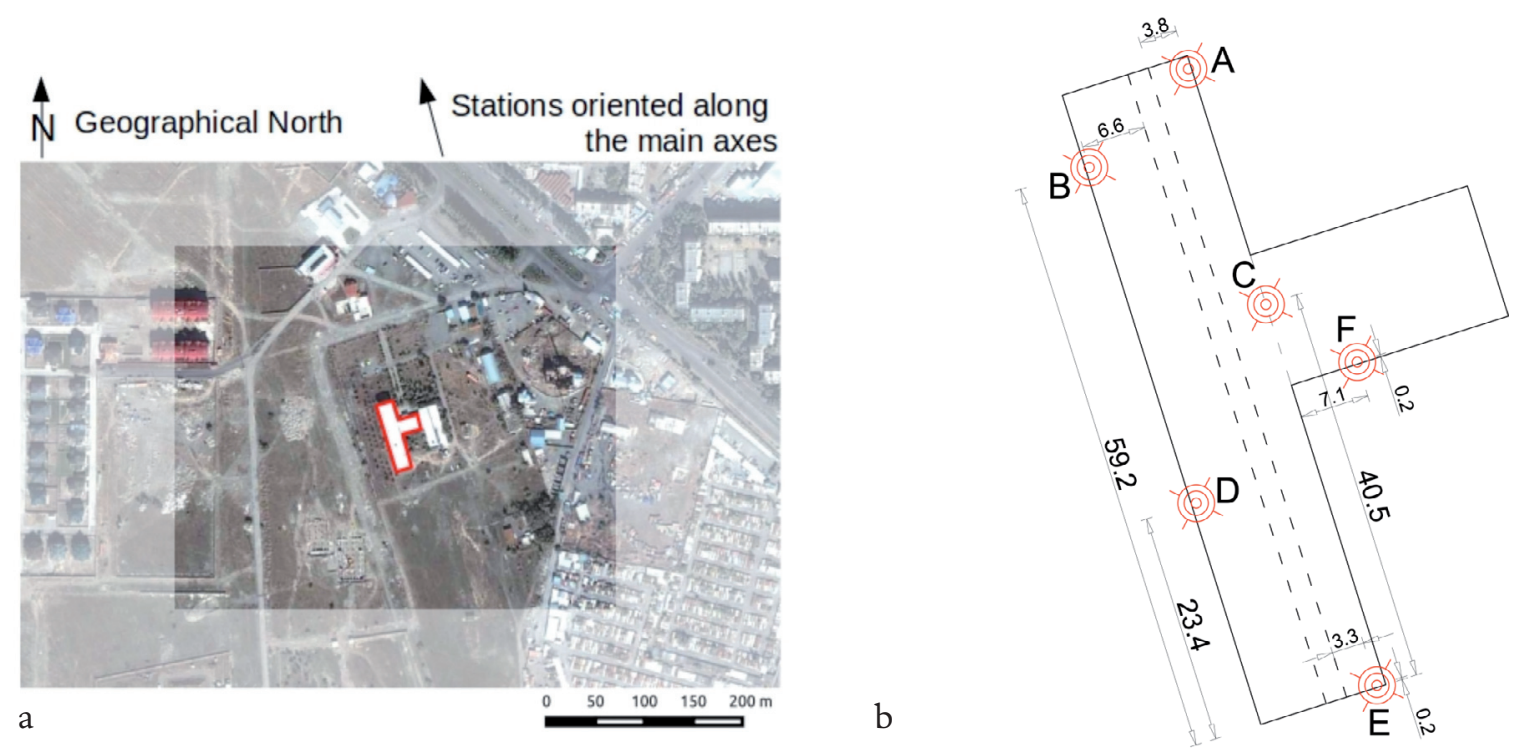

Figure 10. (a) Satellite image and (b) simplified building floor plan of KIS (Figure 2,VII), showing the locations of the installed stations (red symbols).

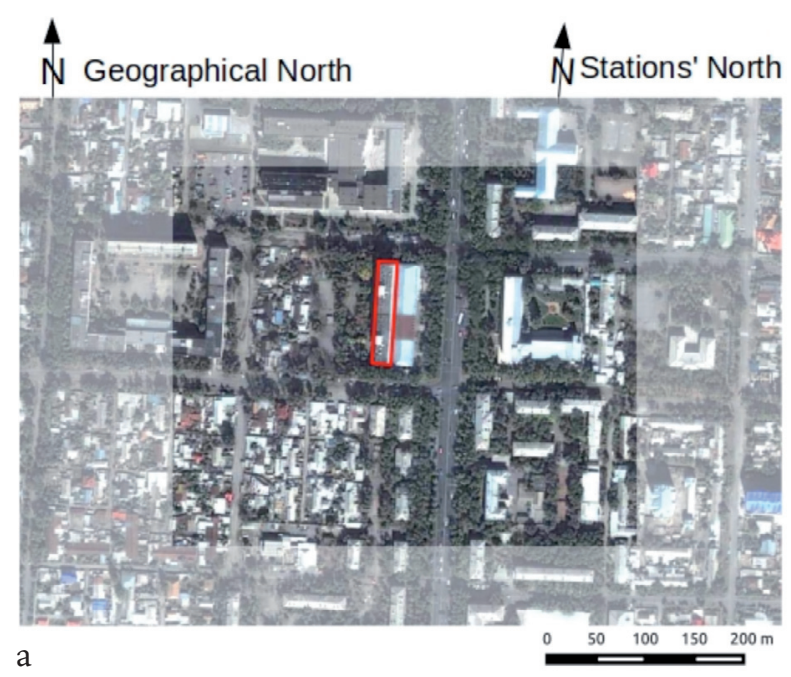

$\mathrm{b}$

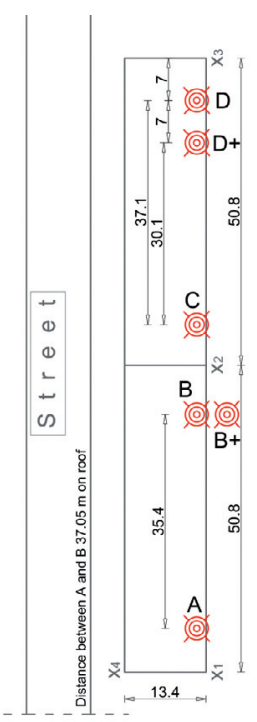

Figure 11. (a) Satellite image and (b) simplified building floor plan of 12 story RC building complex (Figure 2,VIII), showing the locations of the installed stations (red symbols). 


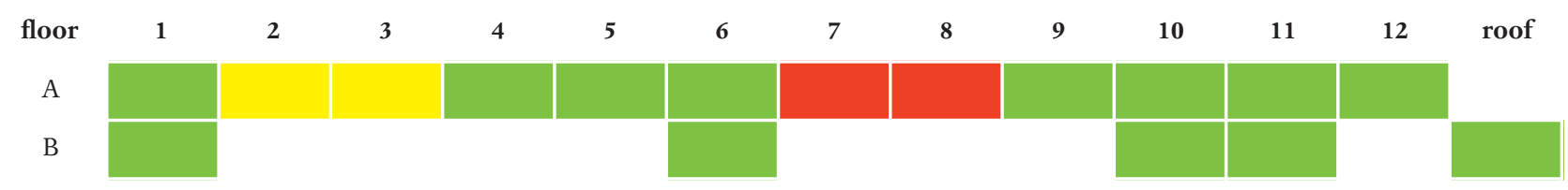

Table 1. Positions and functionality of all stations installed at locations A and B in the 12 story monolitic RC building. Green: station installed and working; yellow: station working, but with no GPS synchronization; red: station not working.

tions had problems receiving the GPS signal and cannot be used for analysis where time synchronization is needed.

VII) For KIS (Figure 8b), the measurements were performed only in 2 buildings of the complex, with 17 instruments. At positions A-E three stations were monitoring the vibrations of the buildings at three different floors, at position $\mathrm{F}$ two stations were installed at two floors. Three stations had problems with the GPS reception (Figure 10b).

VIII) In the 12 story RC building complex (Figure 8c), 28 stations were installed at four locations in two buildings, with one station installed outside as the reference station (Figure 11b). Due to high summer temperature and the melting of the covering, 3 of the 4 instruments installed on the roof were tilted during the measurements.

Since the aim of this paper is to give a general overview of the performed experiment, in the remainder of the paper, only some preliminary analyses for the 12 story monolitic RC building (Figure $2 \mathrm{a}$ ) will be shown. This building is chosen because it is a representative residential house in Dushanbe.

\section{Spectral analysis}

To identify the natural frequencies of the building, the standard approach of calculating the Fourier amplitude spectra is applied [e.g., Kohler et al. 2005, Prieto et al. 2010]. The Fourier amplitude spectra are computed for the two horizontal ( $x$ and $y$-direction) components and the vertical component using a moving window of about 2 minutes, an overlap of $50 \%$, and cosine-tapering at both ends.

In Figure 12 the Fourier amplitude spectra are shown for four frequency ranges $(\mathrm{f}=1.3-2.0 \mathrm{~Hz}, \mathrm{f}=$ 2.0-2.5 Hz, $\mathrm{f}=4.0-9.5 \mathrm{~Hz}$ and $\mathrm{f}=9.5-14 \mathrm{~Hz}$ ) for all sensors installed at position $\mathrm{A}$ at different floors in the 12 story RC building. In the first frequency range, the first two bending modes in the $x$ (blue lines) and $y$-directions (red lines) directions are identified at frequencies of $\mathrm{f}_{1}=$ $1.75 \mathrm{~Hz}$ and $\mathrm{f}_{2}=1.79 \mathrm{~Hz}$, with the amplitudes increasing with increasing height of the floors. For a twofold symmetric structure, the two orthogonal bending modes should be coincident. However, for this building, the symmetry is disturbed by the location of the staircase (see Figure 3b). Therefore, the modes in the two directions are close, but not identical. In the second frequency range, there is a peak at $\mathrm{f}_{3}=2.24 \mathrm{~Hz}$ in both horizontal components with increasing amplitude from lower to upper floors. From the Fourier amplitude spectra, either a torsional mode or a coupled bending mode can be expected. In the third column of Figure 12 , the second bending modes at frequencies $\mathrm{f}_{4}=5.86$ $\mathrm{Hz}$ and $\mathrm{f}_{5}=6.25 \mathrm{~Hz}$ show up mainly in the $x$ and $y$ components, respectively, are shown. The amplitudes increase with the floor level reaching a maximum at the 8th floor and decreasing again in the higher floors until the zero point at the 11th floor is reached. The bending modes are coupled, since at these frequencies there are peaks in both components. The peak in the vertical component at $\mathrm{f}_{6}=8.3 \mathrm{~Hz}$ can be interpreted as tension, since for this frequency no energy in the two horizontal components is present and the amplitude of the vertical component increases with the floors. The fourth column of Figure 12 shows the third bending modes in the $x$ and $y$-directions at frequencies $\mathrm{f}_{8}=12.59 \mathrm{~Hz}$ and $\mathrm{f}_{7}=10.74 \mathrm{~Hz}$, respectively. These two modes are coupled modes, where amplitudes increase with the floor level, decrease after reaching the maximum, and then increase and decrease again, as expected, for a third bending mode.

\section{Operational modal analysis}

Modal analysis is performed to extract the principal dynamic properties, i.e., the natural frequencies and the mode shapes. In this study, a non-parametric identification technique, FDD - Frequency Domain Decomposition [Brincker et al. 2001], an improved version of the Peak Picking (PP) method [Bendat and Piersol 1993], is applied. The cross-power spectral matrix is decomposed into a set of auto spectral density functions by Singular Value Decomposition (SVD). Each of the auto spectral density functions correspond to a single degree of freedom (SDOF) system.

In this study, the FDD is performed for all recordings of all sensors installed at position A and B in the 12 story monolitic RC building (Figure 3). The eigenvectors that correspond to the first three bending modes in $x$ and $y$ directions are shown in Figure 13a and 13b, respectively. A rotational mode is shown in Figure 13c. The first three bending modes in the $x$-direction (Figure 13a) are identified for the frequencies $\mathrm{f}_{1}=1.75 \mathrm{~Hz}, \mathrm{f}_{4}=5.86 \mathrm{~Hz}$ 

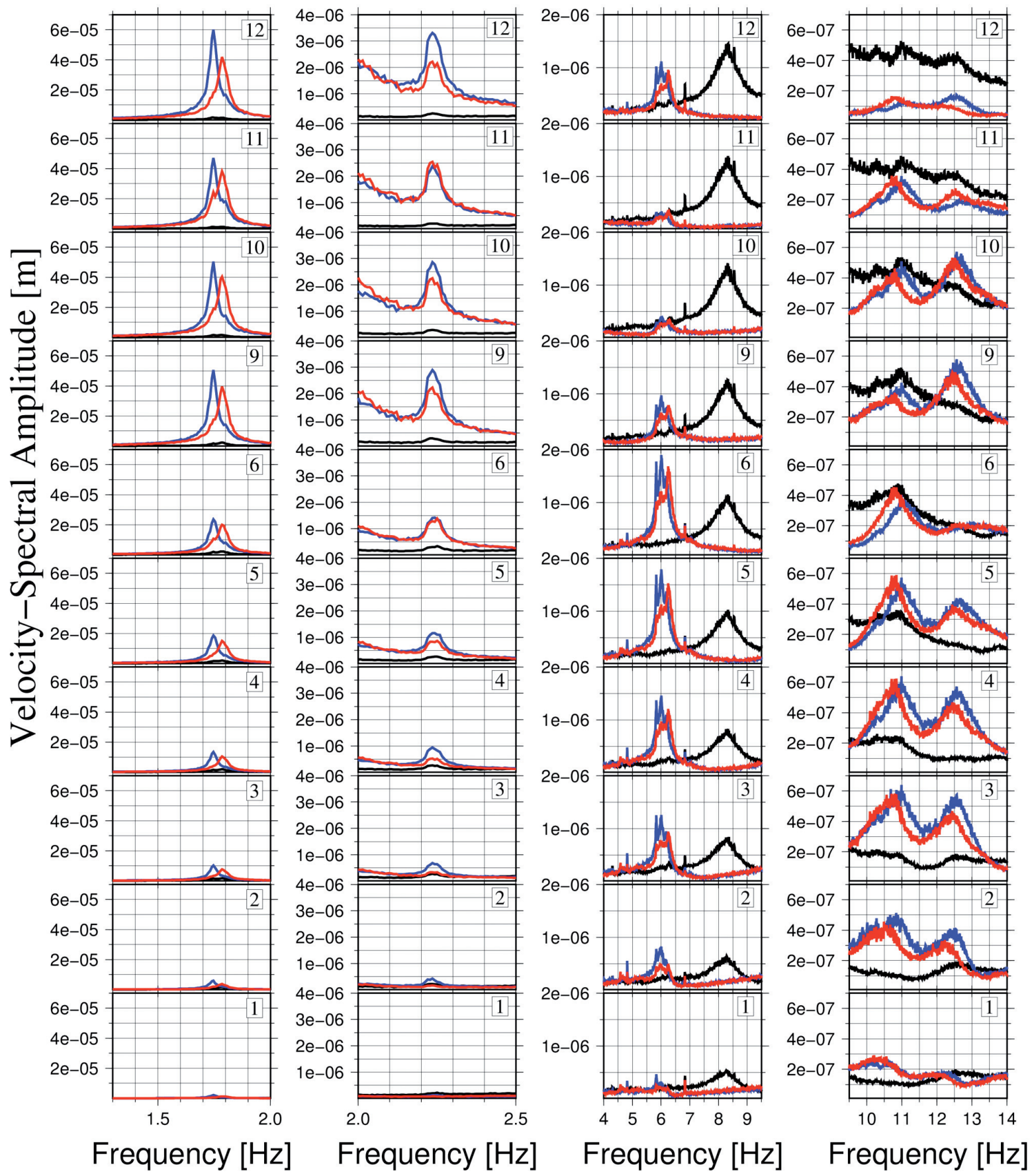

Figure 12. Average spectra computed for the sensors installed inside the 12 story monolitic RC building at position A for four different frequency ranges. The spectra are plotted from the 1st floor (lowermost panel) to the 12th floor (uppermost panel). The three colors (blue, red and black) correspond to the $x, y$ and vertical components. 1st column: $\mathrm{f}=1.3-2.0 \mathrm{~Hz}$, 2nd column: $\mathrm{f}=2.0-2.5 \mathrm{~Hz}, 3 \mathrm{rd}$ column: $\mathrm{f}=4.0-9.5$ $\mathrm{Hz}$ and 4th column: $\mathrm{f}=9.5-14.0 \mathrm{~Hz}$.

and $\mathrm{f}_{8}=12.59 \mathrm{~Hz}$. The second and third bending modes are coupled bending modes whose main direction of motion is in $x$-direction. The first three bending modes in mainly the $y$-direction (Figure 13b) are found at frequencies $\mathrm{f}_{2}=1.79 \mathrm{~Hz}, \mathrm{f}_{5}=6.25 \mathrm{~Hz}$ and $\mathrm{f}_{7}=10.74 \mathrm{~Hz}$. The second and third bending modes are coupled bending modes. If there is also a contribution of rotation to the coupled bending modes, this cannot be identified because of the sparse available data. It is worth mentioning that position $\mathrm{A}$ is located inside the building and hence, located near the axis of rotation. For this reason, the sensors installed at this position record little motion at this frequency, as can be seen for the rotational mode at $\mathrm{f}_{3}=2.24 \mathrm{~Hz}$ (Figure 13c).

\section{Interferometry}

Under assumption of a linear and time invariant system, seismic interferometry, based on the deconvolution of a signal recorded at a reference location $\mathrm{u}_{\text {ref }}(\omega)$ with the recording at a generic location $u(\omega)$ in the frequency domain, is used to determine the impulse response function (IRF). 


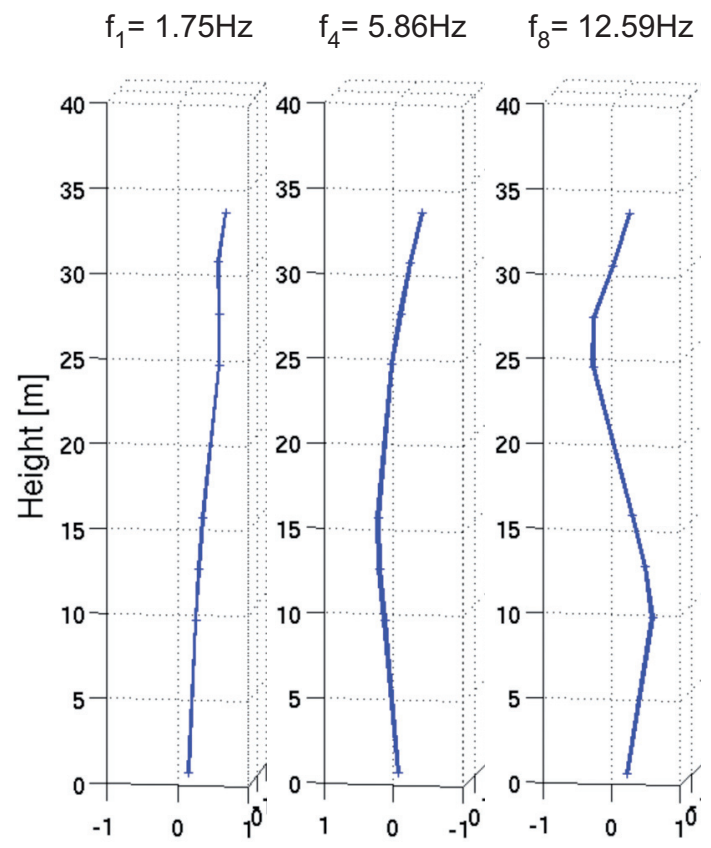

a

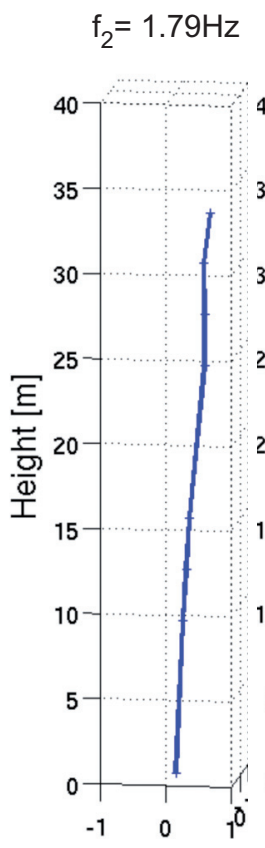

$f_{5}=6.25 \mathrm{~Hz}$

$f_{7}=10.74 \mathrm{~Hz}$

$f_{3}=2.23 \mathrm{~Hz}$

b

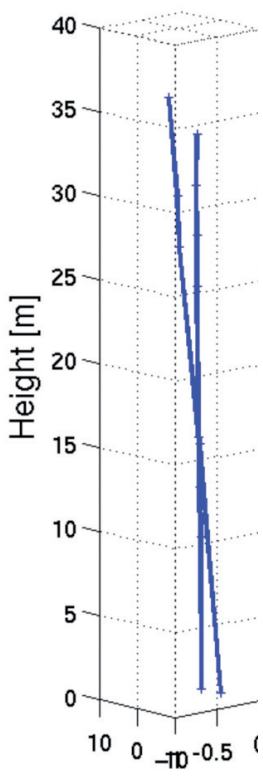

C

Figure 13. Eigenvectors corresponding to the first three bending modes for (a) the $x$ and (b) $y$-direction. (c) First rotational mode.

In the frequency domain, the IRF can be written as

$$
D(\omega)=\frac{\mathrm{u}(\omega) \mathrm{u}^{*}{ }_{r e f}(\omega)}{\left(\mathrm{u}_{r e f}(\omega)\right)^{2}+\varepsilon}
$$

[Snieder and Safak 2006], where $\omega=2 \pi \mathrm{f}$ is the angular frequency and $\varepsilon$ is a regularization parameter, that controls the degree of filtering applied to stabilize the deconvolution.

The interferometric approach can be applied to earthquake recordings [e.g., Snieder and Safak 2006, Newton and Snieder 2012, Nakata et al. 2013] and to ambient vibration measurements [e.g., Prieto et al. 2010, Nakata and Snieder 2014] to extract characteristics of the wave propagation inside a building, like the shear wave velocity and attenuation. When applying the approach to earthquake data, the dependency on the source excitation and the effect of soil-building coupling are removed [Snieder and Safak 2006, Nakata et al. 2013]. For ambient vibration, since there are several simultaneous sources of noise inside a building, the deconvolved waveforms obtained by the interferometric approach could depend on ground coupling [Nakata and Snieder 2014].

One hour of ambient vibration is used to calculate the IRF, using a moving window of about 30 s and an overlapping of $50 \%$. The spectra are filtered in a range of [0.5-20] Hz. A stacking procedure is applied for the deconvolution computed for different time windows to obtain stable impulse response functions. In this study, the regularization parameter $\varepsilon$ (Equation 1) is set to $10^{-3}$ times the average spectral ratio of the recordings at the reference station [Bindi et. al. 2014]. The deconvolution is performed for location B in the $x$ (Figure 14a) and $y$ directions (Figure 14b) with respect to the recordings on the roof. Although at position A more instruments were installed, for this position, the recordings on the roof are missing, which leads to more complex interferometric patterns that are more difficult to interpret. Therefore, these will not be shown in this paper. The IRFs are characterized by the clear propagation of up and down-going waves for the $x$ and the $y$-direction. The up and downgoing waves are marked by green lines for both directions (Figure 14). The velocities are not the same for the whole building, for the lower part of the building (ground floor to the 11th floor) the velocities are marked by green lines, there are changes of velocity in the last floors (between the 11th floor and the roof), marked by a gray dotted line.

For the determination of the shear wave velocity in the $x$ and $y$-directions, the time lag between up and down-going pulses is estimated. The IRFs of both directions are used separately. In Figure 15, the time-lags are plotted versus the distance of each considered sensor to the reference sensor at the top and the slowness $u$ (corresponding to the slope of the line) is estimated using a least squares fit. The green line, especially for the $x$-direction, hits very well all points beside the one at $(0,0)$ belonging to the top floor and hence provides a good estimate of the velocity between the ground floor and the 11th floor. We note that the slowness, and hence the velocity, changes in the uppermost floors of the building. Therefore, the building is divided into two layers (from 1st to 11th and from 11th floor to the roof) and the slowness is estimated in the two layers sepa- 

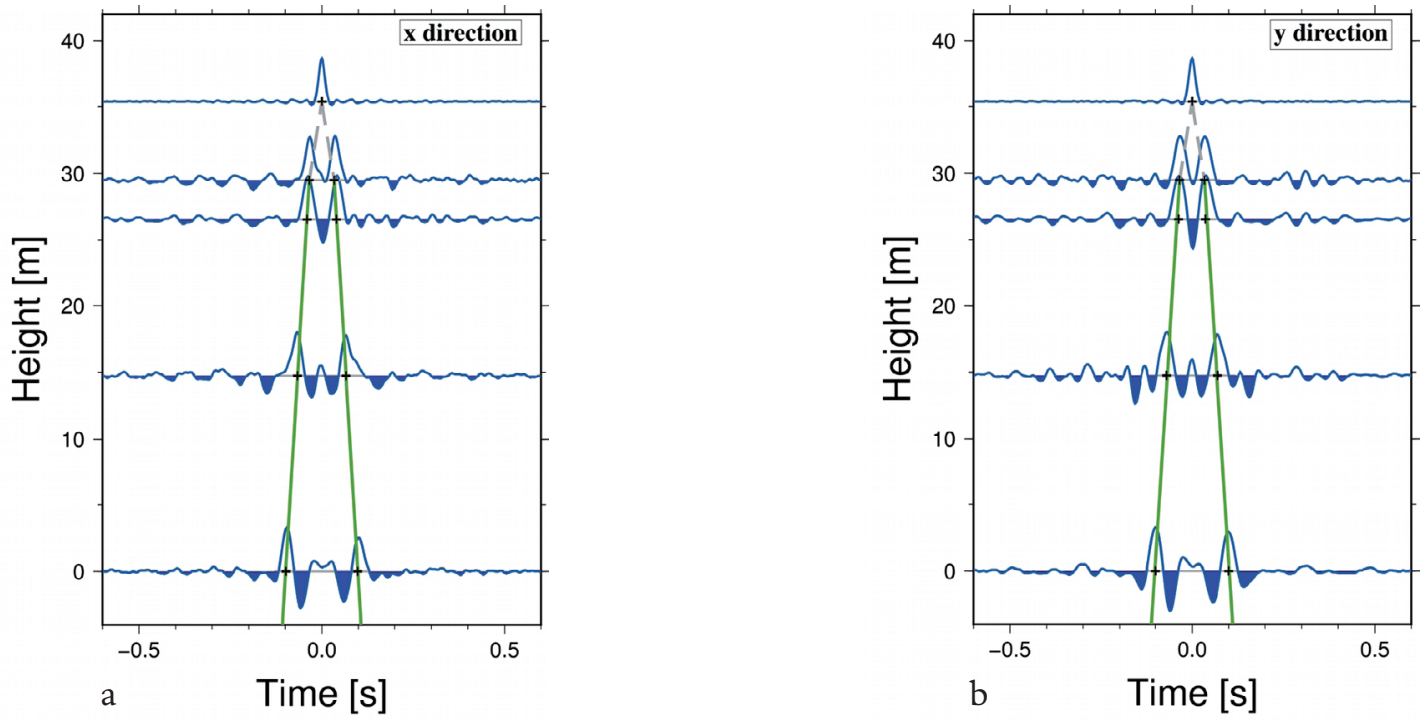

Figure 14. IRFs obtained after deconvolution performed with respect to the 13th floor for position B. (a) $x$ and (b) $y$-directions. The green and dotted gray lines correspond to the wave propagation velocities estimated using the time-lags between the pulses of up and down-going waves.

rately. The velocity is obtained by $\mathrm{v}=1 / \mathrm{u}$. From the 1 st to the 11 th floor, the velocities are estimated as $\mathrm{v}_{x 1}=$ $435 \mathrm{~m} / \mathrm{s}$ and $\mathrm{v}_{y 1}=455 \mathrm{~m} / \mathrm{s}$ for the $x$ and $y$-directions, respectively. For the second layer, the velocity is obtained as $\mathrm{v}_{\{x 1, y 1\}}=174 \mathrm{~m} / \mathrm{s}$ for both directions, but using only two points for the estimation.

\section{Discussion and conclusions}

An overview of a building monitoring experiment performed in Central Asia in the capitals of Kyrgyzstan (Bishkek) and Tajikistan (Dushanbe) is outlined in this study. Several buildings of different construction types, construction years and building heights were instrumented with equipment for ambient vibration measurements. Since some of the buildings were residential houses and it was not possible to access the apartments, the positions of the installed instruments were not always the optimal. For example, optimal locations for locating the rotational modes were not accessible. Furthermore, some stations had problems with receiving the GPS sig- nal (especially inside KSUCTA); therefore, for some stations there was no time synchronization. Such stations can be considered only for some types of analyses where the time synchronization is not required, such as the calculation of the Fourier amplitude spectra. In addition, a few other stations did not work properly due to installation problems. For example, for the 12-story RC building complex in Bishkek (Figure 8h), the stations installed on the roof were tilted due to high summer temperature and the resulting melting of the roofing material.

Despite the above mentioned limitations, the collected data set makes it possible to obtain valuable results about the dynamic characteristics of a representative residential 12 story monolitic RC building constructed in the 1980s in Dushanbe (Figure 2a). Although the experimental set-up was not optimal, the natural frequencies, the vibrational modes and the velocities of wave propagation were detected and the preliminary results are shown in this paper. The spectral analysis of the recordings of sensors installed at different floors, made
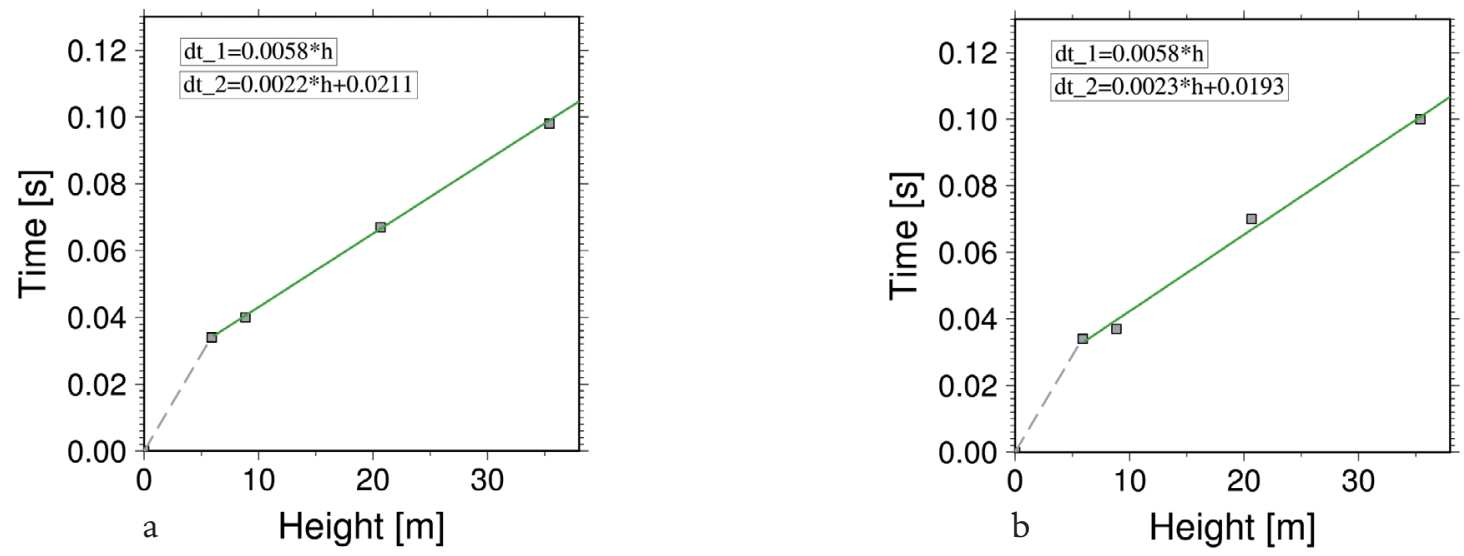

Figure 15. Travel times between the pulses of up and down-going waves at different floors versus the distance of the considered sensor to the sensor at the roof. The slope of the green and the dotted gray lines correspond to the slownesses for a certain layer. (a) $x$ and (b) $y$-direction. 
it possible to identify the natural frequencies of the building and to perform the first identification of the vibration modes. The first three bending modes were identified for both the $x$ and $y$-directions from the spectral amplitude changes at different floors. The peak at $\mathrm{f}_{6}=8.3 \mathrm{~Hz}$ is identified as tension, because there is no significant energy at this frequency on the two horizontal components, but only on the vertical, increasing with the floor level. Unfortunately, because of the limited data set, this mode cannot be identified definitely. The modal analysis was performed by Frequency Domain Decomposition using the recordings of all components of all installed stations. The identification of the first three bending modes for the $x$ and $y$-directions as identified by the spectral analysis was confirmed. In addition, the first rotational mode was identified at $\mathrm{f}_{3}=$ $2.24 \mathrm{~Hz}$. Although a preliminary identification of the modes was possible, it should be noted that the interpretation of the results is limited by the not optimal distribution of sensors. A denser data set with sensors installed at different locations within the building, preferably in the corners or next to exterior walls, would make it possible to study in more detail the vibrational modes and to better understand the movements of the building. Especially, for the identification of rotational modes, stations installed near the rotational axis (i.e., located in the middle of the building) as in position $\mathrm{A}$, do not provide significant information about these modes.

With the interferometric approach, the shear wave velocities for the $x$ and $y$-directions were estimated using the recordings at location $\mathrm{B}$ at different floors in the building. Although fewer stations were installed at location $\mathrm{B}$, these recordings were used, since the recordings on the roof were available at this position. The clear pulses of up and down-going waves in the impulse response function make it possible to identify the velocities easily. A change in the velocities is assumed to take place between the 11th floor and the roof. Since the recordings at the 12th floor are missing, the final identification of the velocity shift is not possible. Moreover, it is worth mentioning that the velocity between the 11th floor and the roof were obtained from only two instrument stations. The velocities estimated by the least squares fit represent well the velocities in the building since the resulting lines (the slope is equal to the slowness) pass near the four points that were taken into consideration. To investigate in more detail a possible variation of velocities between the floors, recordings at each floor are required.

Future work will focus on the results obtained for all monitored buildings (five buildings in Dushanbe and three in Bishkek), analyzing also the link between different building types and heights and their dynamical characteristics. Furthermore, the experiment was repeated, improving upon the experimental set-up and performing denser ambient vibration measurements with a larger number of instruments in five buildings [Petryna et al. 2014]. The data set will be extended by combining the data collected in the two campaigns.

Acknowledgements. The authors wish to thank CAIAG and IGEES for the collaboration, and to all our colleagues who supported and participated in the experiment. A special thanks to the people in Bishkek and Dushanbe who allowed the measurements in their homes. The instruments were provided by the GIPP instrumental pool and the experiment was funded by the GCO-CA initiative of GFZ and by the EMCA-Earthquake Model Central Asia project. K. Fleming kindly revised our English. The authors would like to thank an anonymous reviewer for his/her comments.

\section{References}

Abrakhmatov, K., H.-B. Havenith, D. Delvaux, D. Jongmans and P. Trefois (2003). Probabilistic PGA and Arias intensity maps of Kyrgyzstan (Central Asia), J. Seismol., 7, 203-220.

Bendat, J.S., and A.G. Piersol (1993). Engineering Applications of Correlation and Spectral Analysis, John Wiley \& Sons.

Bindi, D., M. Mayfield, S. Parolai, S. Tyagunov, U.T. Begaliev, K. Abdrakhmatov, B. Moldobekov and J. Zschau (2011). Towards an improved seismic risk scenario for Bishkek, Kyrgyz Republic, Soil Dyn. Earthq. Eng., 31, 521-525.

Bindi, D., K. Abdrakhmatov, S. Parolai, M. Mucciarelli, G. Grünthal, A. Ischuk, N. Mikhailova and J. Zschau (2012). Seismic hazard assessment in Central Asia: outcomes from a site approach, Soil Dyn. Earthq. Eng., 37, 84-91.

Bindi, D., B. Petrovic, S. Karapetrou, M. Manakou, T. Boxberger, D. Raptakis, K. Pitilakis and S. Parolai (2014). Seismic response of an 8 story RC building from ambient vibration analysis, B. Earthq. Eng.; doi:10.1007/s10518-014-9713-y.

Bindi, D., T. Boxberger, S. Orunbaev, M. Pilz, J. Stankiewicz, M. Pittore, I. Iervolino, E. Ellguth and S. Parolai (2015). On-site early-warning system for Bishkek (Kyrgyzstan), Annals of Geophysics, 58 (1), S0112; doi:10.4401/ag-6664.

Brincker, R., L. Zhang and P. Andersen (2001). Modal identification from Ambient Responses using Frequency Domain Decomposition, Smart Mater. Struct., 10, 441-445.

Cheng, M.H., M.D. Kohler and T.H. Heaton (2015). Prediction of Wave Propagation in Buildings Using Data from a Single Seismometer, B. Seismol. Soc. Am.; doi:10.1785/0120140037.

Erdik, M., T. Rashidov, E. Safak and A. Turdukulov (2005). Assessment of seismic risk in Tashkent, 
Uzbekistan and Bishkek, Kyrgyz Republic, Soil Dyn. Earthq. Eng., 25, 473-486.

GeoHazards International (1997). Lessons for Central Asia from Armenia and Sakhalin, GeoHazards International, Stanford, USA.

Kondorskaya, N.V., and N.V. Shebalin (1982). New Catalog of Strong Earthquakes in the U.S.S.R. from Ancient Times through 1977, World Data Center A for Solid Earth Geophysics, Boulder, 608 pp.

Kohler, M.D., P. Davis and E. Safak (2005). Earthquake and Ambient Vibration Monitoring of the Steel Frame UCLA Factor Building, Earthq. Spectra, 21 (3), 715-736.

Nakata, N., R. Snieder, S. Kuroda, S. Ito, T. Aizawa and T. Kunimi (2013). Monitoring a building using deconvolution interferometry, I: Earthquake-data analysis, B. Seismol. Soc. Am., 103, 1662-1678.

Nakata, N., and R. Snieder (2014). Monitoring a building using deconvolution interferometry, II: Ambient vibration analysis, B. Seismol. Soc. Am., 104, 204-213.

Newton, C., and R. Snieder (2012). Estimating intrinsic attenuation of a building using deconvolution interferometry and time reversal, B. Seismol. Soc. Am., 5, 2200-2208.

Niyazov, J., P. Yasunov, M. Wieland and M. Pittore (2014). A contribution to the refinement of the exposure model for Dushanbe, Tajikistan, GISCA-2014 conference, Urumqi, China.

Nurmagambetov, A., N. Mikhailova and W. Iwan (1999). Seismic hazard of the Central Asia region, In: S.A. King, V.I. Khalturin, B.E. Tucker (eds.), Seismic hazard and building vulnerability in post-Soviet Central Asian republics, Nederlands, Kluwer Academic Publishers, 1-43.

Parolai, S., D. Bindi, T. Boxberger, C. Milkereit, K. Fleming and M. Pittore (2015). On-Site Early Warning and rapid damage forecasting using single stations: outcomes from the REAKT project, Seismol. Res. Lett., under review.

Petryna, Y., D. Bindi, B. Petrovic, S. Orunbaev, T. Sheraliev, A. Mostböck and U. Begaliev (2014). Dynamic response of buildings in Bishkek using ambient vibration and finite element modeling, Remote and Ground-based Earth Observations in Central Asia, dedicated to the 10-year anniversary of CAIAG.

Pilz, M., D. Bindi, T. Boxberger, F. Hakimov, B. Moldobekov, S. Murodkulov, S. Orunbaev, M. Pittore, J. Stankiewicz, S. Ullah, F. Verjee, M. Wieland, P. Yasunov and S. Parolai (2013). First Steps toward a Reassessment of the Seismic Risk of the City of Dushanbe (Tajikistan), Seismol. Res. Lett., 84, 1026-1038.

Pittore, M., and M. Wieland (2013). Toward a rapid probabilistic seismic vulnerability assessment using satel- lite and ground-based remote sensing, Nat. Hazards, 68, 115-145.

Prieto, G.A., J.F. Lawrence, A.I. Chung and M.D. Kohler (2010). Impulse response of civil structures from ambient noise analysis, B. Seismol. Soc. Am., 100, 2322-2328.

Snieder, R., and E. Safak (2006). Extracting the building response using interferometry: theory and applications to the Millikan Library in Pasadena, California, B. Seismol. Soc. Am., 96, 586-598.

Ullah, S., D. Bindi, M. Pilz, L. Danciu, G. Weatherill, E. Zuccolo, A. Ischuk, N.N. Mikhailova, K. Abdrakhmatov and S. Parolai (2015). Probabilistic seismic hazard assessment of Central Asia, Annals of Geophysics, 58 (1), S0103; doi:10.4401/ag-6687.

Ulomov, V.I., and the GSHAP Region 7 Working Group (1999). Seismic hazard of Northern Eurasia, Annali di Geofisica, 42 (6), 1023-1038.

Wieland, M., M. Pittore, S. Parolai, J. Zschau, B. Moldobekov and U. Begaliev (2012). Estimating building inventory for rapid seismic vulnerability assessment: towards an integrated approach based on multisource imaging, Soil Dyn. Earthq. Eng., 36, 70-83.

Zubovich, A.V., X.-Q. Wang, Y.G. Scherba, G.G. Schelochkov, R. Reilinger, C. Reigber, O.I. Mosienko, P. Molnar, W. Michajljow, V.I. Makarov, J. Li, S. I. Kuzikov, T.A. Herring, M.W. Hamburger, B.H. Hager, Y. Dang, V.D. Bragin, R.T. Beisenbaev (2010). GPS velocity field for the Tien Shan and surrounding regions, Tectonics, 29 (6), TC6014.

\footnotetext{
${ }^{\star}$ Corresponding author: Bojana Petrovic,

Helmholtz Center Potsdam - German Research Center for Geosciences, Potsdam, Germany; email: petrovic@gfz-potsdam.de.

C 2015 by the Istituto Nazionale di Geofisica e Vulcanologia. All rights reserved.
} 